Bull. Egypt. Soc. Physiol. Sci. Vol. (41), Issue (4), 484-499

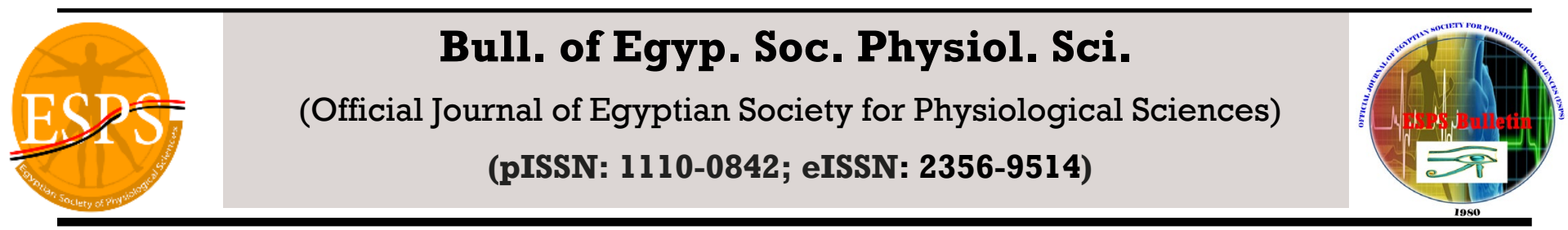

\title{
Possible Ameliorative Effects of Silymarin on Gibberellic Acid-induced Pancreatic Dysfunction in Adult Female Rats and their Pups
}

\author{
Heba M. Galal ${ }^{1,2, *}$, Manal M. Sayed ${ }^{3}$, Asmaa M.S. Gomaa ${ }^{1}$ \\ ${ }^{1}$ Medical Physiology Department, Faculty of Medicine, Assiut University, Assiut, Egypt \\ ${ }^{2}$ Department of Medical Physiology, College of Medicine, Jouf University, Sakaka, Saudi Arabia \\ ${ }^{3}$ Histology and Cell Biology Department, Faculty of Medicine, Assiut University, Assiut, Egypt
}

Submit Date: Dec 20, 2020

Revise Date: Jan 18, 2021

Accept Date: April 2, 2021

Keywords

- Gibberellic acid

- Pancreas

- Rats

Silymarin

\section{Abstract}

Background: Gibberellic acid (GA3) is frequently applied in agriculture to stimulate flowering \& fruit growth. Owing to its persistence in the soil for months, it may cause harm to human health. Silymarin is a herbal drug commonly known as hepatoprotective agent. Aim: To reveal the outcomes of exposure to GA3 on the pancreatic functions in late days of gestation and early lactation and to elucidate the possible protective role of silymarin on these alterations if present and the pathophysiological pathways. Materials and Methods: 18 lactating Albino rats \& 18 pups were classified into control group, GA3-treated group: received GA3 dissolved in drinking water $(55 \mathrm{mg} / \mathrm{kg} / \mathrm{day})$, and silymarin \& GA3-treated group: administered both GA3 \& $100 \mathrm{mg} / \mathrm{kg}$ silymarin during the last week of pregnancy $\&$ the first 2 weeks of lactation. Serum levels of glucose, insulin \& amylase were measured. Pancreatic tissue homogenate was used for the assessment of malondialdehyde (MDA), superoxide dismutase (SOD), and catalase (CAT), interleukin-1 $\beta$ (IL-1 $\beta$ ) \& tumor necrosis factor-alpha (TNF- $\alpha$ ). Additionally, pancreatic specimens were processed for histological examination. Results: Administration of GA3 impaired pancreatic functions in dams and pups namely, elevated serum levels of glucose and amylase \& reduced insulin levels accompanied with significant increased oxidative stress \& inflammatory markers in pancreatic homogenate and altered the general histological pancreatic appearance. Co-treatment with silymarin potently improved these biochemical \& histological alterations. Conclusion: Silymarin attenuates GA3-induced alterations in pancreatic functions through cytoprotecting actions on pancreatic exo- and endo-crine cells.

Corresponding author: Heba M. Galal ${ }^{1,2, *}$ Medical Physiology Department, Faculty of Medicine, Assiut University, Assiut, Egypt. Department of Medical Physiology, College of Medicine, Jouf University, Sakaka, Saudi Arabia.Tel: 002/01000788437 0966/0580490311. E-mail: hebamgalal17@aun.edu.eg 


\section{INTRODUCTION}

Agricultural pollution is increasing worldwide especially in the developing countries. The most common chemicals used in agriculture to improve plant growth are plant growth regulators (PGR), also, called plant hormones (1). Plants can manufacture these hormones naturally to ensure their normal growth (2). Gibberellic acid (GA3) is a natural PGR, first extracted from fungus "Fusarium", most widely used in Egypt \& other countries in agriculture as described by ChaariRkhis et al. (3) to accelerate the crop of plants by boosting cell division, augmenting the synthesis of DNA, and causing the enlargement of leaves (4). The world health organization (WHO) considered GA3 as a chemical related to pesticides. Due to its persistence \& bioactivity in the soil for months, low doses are only permitted (5). People may be subjected to residues of GA3 and other PGRs via intake of food stuffs containing these chemicals especially the fresh fruits and vegetables as well as through drinking water. As it is easily absorbed dermally, orally or by inhalation, it may cause damage to various internal organs e.g. liver, kidney, and brain tissues $(6,7)$. Although extensively used in agriculture, little information is available about the possible mechanisms of the hazardous effects of GA3 on human health (8). Oxidative stress with increased production of free radicals may be a proposed mechanism of GA3 toxicity causing cell damage $(9,10)$.

Diabetes mellitus (DM) is an increasing problem worldwide. About $90 \%$ of cases have type $2 \mathrm{DM}$ while the remaining $10 \%$ of cases are due to type $1 \mathrm{DM}$ or gestational DM (11). Another type of DM that is still unclear to scientists is called Type 3c DM (T3cDM) and is usually misdiagnosed as T2DM. Its pathogenic mechanism is related to the presence of pancreatic inflammation followed by fibrosis that alters its exocrine function with inadequacy of enzymes and its endocrine function with a lack of insulin (12). During the period from 2013 to 2035, a rise of 56 $\& 20 \%$ in the number of adults with diabetes might exist in developing and developed countries, respectively (13). In Egyptian society, around $10.4 \%$ of the Egyptian population (aged 10-79 years) has DM (14). By the year 2030 in Egypt, it is expected that about 8.6 million adults will have DM (15). The real reasons explaining this rapid increase in DM are still unknown but the increased exposure to environmental toxic chemicals such as agricultural pollution, toxic heavy metals, and organic pollutants are incriminated (16).

There is widespread awareness to use natural herbal compounds instead of medications for the treatment of various disease conditions as they are safe, low cost, effective, and with less complications and an increased rate of survival (17). Silymarin is a natural herb derived from Silybum marianum seeds widely cultivated around the world (18). It is frequently utilized as a treatment of different diseases of the liver because of its active ingredients namely; silydianin, silychristin, isosilybin A, isosilybin B and silybin (19). Silymarin's antioxidant in addition to inflammation lowering properties in vitro and in vivo are believed to be the basis for its therapeutic efficiency against DM (20). Moreover, it has also several beneficial properties such as renoprotective, hypolipidemic, anti-atherosclerotic, osteoprotective, anti-cancer activities (21). 
A limited number of studies about the pancreatic dysfunction in adult animals subjected to GA3 was performed and no study was carried out on the pancreatic functions in the offsprings of mothers exposed to GA3 during late days of gestation and early lactation. Hence, this work aimed to reveal the possible toxic influences of prenatal and early postnatal exposure to GA3 on the pancreatic functions and to elucidate the possible protective role of silymarin on these alterations if present and the involved pathophysiological pathways.

\section{Materials and methods:}

\section{Chemicals:}

Gibberellic acid, silymarin, and carboxymethylcellulose (CMC) were bought from Sigma-Aldrich Co (St. Louis, MO, USA). Gibberellic acid, in the form of white crystalline powder, was dissolved in drinking water. Silymarin was suspended in $0.5 \%$ CMC.

\section{Experimental Animals:}

A total of 9 male and 18 female healthy Wistar albino rats, 10-12 weeks of age and with an average weight of 180-200 g, were enrolled in this study. They were placed at average room temperature $\left(22 \pm 2{ }^{\circ} \mathrm{C}\right)$ in properly ventilated cages (up to 4 per cage) under a natural 12:12-h light-dark rhythm at the Animal House of the Faculty of Medicine, Assiut University. They had free access to water and standard rat chow (composed of $71 \%$ corn, $2 \%$ soybean, $22 \%$ wheat bran, $4 \%$ sunflower oil, $0.5 \%$ common salt, and $0.5 \%$ premix) during the experiment. The local Ethics Committee at Faculty of Medicine, Assiut University, Assiut, Egypt approved the study design and the authors strictly followed the institutional standards of dealing with animals during the whole study period.

\section{Experimental design:}

Separation between the adult male and female rats was performed for 3 weeks to ensure that the female rats were not pregnant. The proestrous phase of the estrous cycle was identified via taking a vaginal smear from upper vagina and spread it over glass slides. Then, slides were stained with haematoxylin \& eosin, dehydrated, and examined with light microscope (22) for the presence of clusters of large round nucleated epithelial cells. Female rats during their pro-estrous phase were housed overnight with the males in a proportion of two females : one male in clean properly aerated plastic cages. Early in the next morning, smears obtained from the vagina were examined for the detection of spermatozoa. If sperms were detected, this was considered as day "zero" of gestation (GD0) (23). Eighteen pregnant rats were caged separately till term and were distributed randomly into 3 equal groups.

1- Control group: They received tap water and $0.5 \mathrm{~mL}$ of $0.5 \% \mathrm{CMC}$ via orogastric tube for 21 days starting at the $14^{\text {th }}$ day of gestation (one week during pregnancy and two weeks after delivery).

2- GA3-treated group: They were administered oral GA3 daily at a dose of $55 \mathrm{mg} / \mathrm{Kg}$ body weight for 21 days starting at the $14^{\text {th }}$ day of gestation by orogastric tube (one week during pregnancy and two weeks after delivery). This dosage was selected to produce unleathal toxic effects in suckling pups whose mothers received GA3 (24).

3- Silymarin \& GA3-treated group: They received GA3 in the same way and dose as the 
previous group and concurrently administered oral silymarin by orogastric tube at a dose of $100 \mathrm{mg} / \mathrm{kg}$ body weight as described by Turgut et al (25) for 21 days starting at the $14^{\text {th }}$ day of gestation (one week during pregnancy and two weeks after delivery).

\section{Sample collection:}

Fourteen days after delivery, all dams and 6 pups of their offspring in each group were anesthetized by smelling a piece of cotton immersed in chloroform, then sacrificed by cervical dislocation. Blood samples from fasted rats were taken, centrifuged at $3000 \mathrm{~g}$ for 15 minutes, and the non-haemolysed supernatant sera were removed and retained at $-20{ }^{\circ} \mathrm{C}$ until further use. The pancreas was removed from both dams and pups, washed with ice-cold saline, and split into two parts. One part was frozen in liquid nitrogen and stored at $-80{ }^{\circ} \mathrm{C}$ for later analysis. The other part was inserted for 48 hours in 10 percent neutral buffered formalin. Specimens were then processed for paraffin blocks. $5 \mu \mathrm{m}$ paraffin sections were cut serially with a microtome (Leica RM 2125RT, Germany). Sections were stained with hematoxylin \& eosin (H\&E) for general histological structure (Drury and Wallington, 1980). The number of Langerhans' islets in the pancreas/field was counted in H\&E-stained slides using a computer-connected Olympus optical microscope (Olympus, Center Valley, PA, USA) fitted with a digital Olympus U-CMAD3 camera. In each group, a minimum of 10 fields in each section was examined per animal.

\section{Biochemical measurements:}

Measurement of serum glucose level: It was assayed by ready-to-use commercially available enzymatic colorimetric assay kit (Bio-Diagnostics,
Egypt, Cat. No. GL 1320). The degree of the formed color is in proportion to the concentration of glucose in the sample. Data were presented as $\mathrm{mg} / \mathrm{dl}$.

Measurement of serum insulin level: Serum insulin level was estimated by specific enzyme linked immune assay (ELISA) kit for rat's insulin (Millipore Corporation, Billerica, MA) according to the manufacturer's instructions. Data were expressed as $\mu \mathrm{IU} / \mathrm{ml}$.

Measurement of serum amylase level: It was measured with a spectrophotometry via the Olympus AU-2700 auto analyzer (Olympus, Homburg, Germany) using commercial kits (BioDiagnostics, Egypt, Cat. No. AY 1050). Values were presented as $\mathrm{U} / \mathrm{L}$.

\section{Measurement of pancreatic oxidative stress and} inflammatory biomarkers: The pancreatic tissues were weighed, homogenized in an ice-cold phosphate buffer saline, and then centrifuged for 10 min at $3000 \mathrm{rpm}$ at $4^{\circ} \mathrm{C}$. The supernatant was taken for the assessment of the oxidative stress and inflammatory biomarkers. Malondialdehyde (MDA), superoxide dismutase (SOD), and catalase (CAT) were colorimetrically assessed by commercially available kits (Bio-Diagnostics, Egypt, Cat. No. MD 2529, SD 2521, and CA 2517; respectively) following the manufacturer's protocol. Results of MDA were presented as $\mathrm{nM} / \mathrm{mg}$ protein and SOD and CAT were expressed as $\mathrm{U} / \mathrm{mg}$ protein. IL- $1 \beta$ and TNF- $\alpha$ were estimated using ELISA kits (Koma Biotech, Seoul, Korea) according to the manufacturer's instructions. Levels of IL-1 $\beta$ were presented as $\mathrm{ng} / \mathrm{mg}$ protein and levels of TNF- $\alpha$ were expressed as $\mathrm{pg} / \mathrm{mg}$ protein. Total protein in the pancreatic homogenate was determined via biuret reagent (26). 


\section{Statistical analysis:}

The results were analyzed with SPSS version 16 (SPSS Inc., Chicago, USA). All values were presented as means \pm standard deviation (SD). Differences among the groups were compared by one way analysis of variance (ANOVA) test followed by Tukey's post hoc test. The significant level was adjusted at $\mathrm{P}$ value $\leq$ 0.05 .

\section{Results:}

The effects of GA3 and silymarin on serum glucose, amylase, and insulin levels in dams and their pups:

Our results showed that serum glucose and amylase levels were significantly elevated in lactating rats given GA3 compared to the control group $(\mathrm{p}=0.001 \& \mathrm{p}=0.000 ;$ respectively). Administration of silymarin concurrently with GA3 reduced glucose level with no significant difference from the control rats but its level was significantly lower than GA3-treated group $(\mathrm{p}=$ 0.002). Rats in the same group had significantly reduced serum amylase levels in comparison with GA3-treated group $(\mathrm{p}=0.000)$. Regarding serum insulin level, it was significantly decreased in
GA3-treated rats versus the control group $(\mathrm{p}=$ 0.029). Cotreatment with silymarin normalized the blood insulin level with no significant difference from the control group and showed a significant higher level than the GA3-treated group $(\mathrm{p}=0.001)$ (Table 1).

In the offspring of mothers given GA3, the levels of glucose \& amylase increased significantly in comparison to the control group ( $\mathrm{p}$ $=0.002 \& \mathrm{p}=0.017$; respectively). On the other hand, the administration of silymarin simultaneously with GA3 succeeded in decreasing the glucose \& amylase levels to a significant degree versus pups in the GA3-treated group $(\mathrm{p}=$ $0.05 \& p=0.000$; respectively) but this decrease was still insignificant versus pups in the control group. Serum insulin level was significantly reduced in pups in the GA3-treated group in comparison with pups in the control group ( $\mathrm{p}=$ $0.039)$. Interestingly, pups belonging to mothers in the group that received both silymarin and GA3 showed significantly increased serum insulin levels versus pups in the GA3-treated group $(\mathrm{p}=$ 0.001 ). Moreover, the level of insulin in those pups was insignificant versus the control pups (Table 1).

Table (1): Serum levels of glucose, insulin \& amylase in the different studied groups.

\begin{tabular}{|l|c|c|c|}
\hline \multicolumn{4}{|c|}{ Dams } \\
\hline Groups & Glucose $(\mathrm{mg} / \mathrm{dl})$ & Insulin $(\mu \mathrm{IU} / \mathrm{ml})$ & Amylase $(\mathrm{U} / \mathrm{L})$ \\
\hline Control group $(\mathrm{n}=6)$ & $72.5 \pm 7.503$ & $9.05 \pm 2.502$ & $685.17 \pm 122.83$. \\
\hline GA3-treated group $(\mathrm{n}=6)$ & $90.83 \pm 6.105^{\mathbf{a}}$ & $2.03 \pm 0.761^{\mathbf{a}}$ & $1379.2 \pm 346.33^{\mathbf{a}}$ \\
\hline Silymarin \& GA3-treated group $(\mathrm{n}=6)$ & $74 \pm 7.239^{\mathbf{b}}$ & $14.02 \pm 6.82^{\mathbf{b}}$ & $410.17 \pm 71.81^{\mathbf{b}}$ \\
\hline \multicolumn{3}{|c|}{ Pups } & $150.5 \pm 34.52$ \\
\hline Control group (n=6) & $67.83 \pm 13.54$ & $9.98 \pm 2.49$ & $195 \pm 34.94^{\mathbf{a}}$ \\
\hline GA3-treated group (n=6) & $106 \pm 14.81^{\mathbf{a}}$ & $3.35 \pm 1.52^{\mathbf{a}}$ & $89.83 \pm 37.05^{\mathbf{b}}$ \\
\hline Silymarin \& GA3-treated group $(\mathrm{n}=6)$ & $84 \pm 20.84^{\mathbf{b}}$ & $14.77 \pm 6.67^{\mathbf{b}}$ & \\
\hline
\end{tabular}

Data are presented as mean \pm SD ( $\mathrm{n}=6$ for each group). A p value $\leq 0.05$ was considered statistically significant. ${ }^{\text {a: }}$ significant against the control group. ${ }^{\text {b}}$ : significant against GA3-treated group.

The effects of GA3 and silymarin on the

oxidative stress and inflammatory biomarkers

in dams and their pups:
The pancreatic level of MDA was significantly raised in dams given GA3 versus the control group $(\mathrm{p}=0.000)$. Silymarin in conjunction with GA3 resulted in a significant 
reduction in the pancreatic level of MDA in comparison with the GA3-treated group $(\mathrm{p}=$ 0.000). Still, the level of pancreatic MDA in this group was markedly higher than the control group $(p=0.002)($ Fig 1A). On the contrary, GA3-treated rats showed significantly lower levels of the antioxidant enzymes SOD \& CAT when compared to the control group $(p=0.044$, and $p=0.000$; respectively). Silymarin improved the levels of antioxidant enzymes in dams that received GA3 and silymarin. Those rats revealed significant increased levels of both SOD \& CAT versus the GA3-treated group $(\mathrm{p}=0.001$, and $\mathrm{p}=0.000$; respectively). The same dams reported

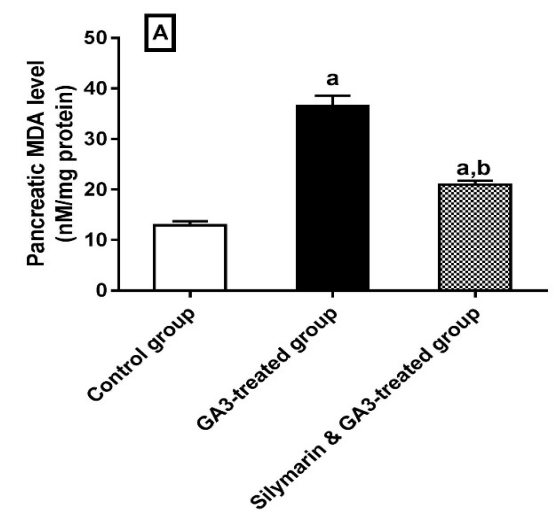

insignificant levels of SOD and significant increased levels of CAT versus the control group $(p=0.003)($ Fig $2 \mathrm{~A} \& 3 \mathrm{~A})$. Levels of IL-1 $\beta$ and TNF- $\alpha$ in the pancreatic tissue homogenate of GA3-treated dams revealed significant elevations when compared with the control group $(p=0.000$ and $\mathrm{p}=0.000$; respectively). Treatment of animals using silymarin with GA3 attenuated the levels of these inflammatory markers versus GA3-treated rats $(\mathrm{p}=0.007$ and 0.044 ; respectively). Despite that improvement, these markers were still significantly more than the control rats $(\mathrm{p}=0.000$, and $\mathrm{p}=0.000$; respectively) (Fig $4 \mathrm{~A} \& 4 \mathrm{C})$.

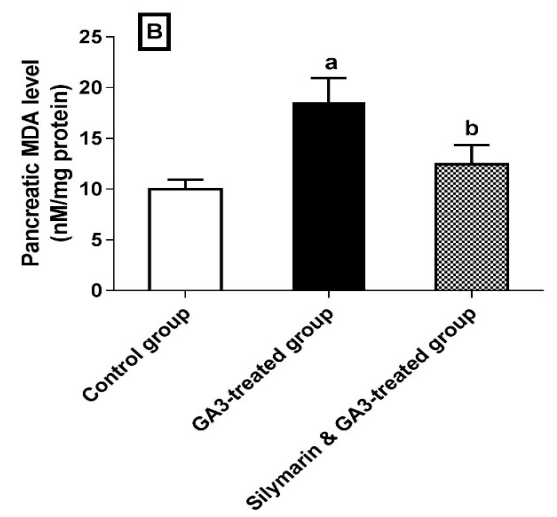

Figure 1: Pancreatic tissue levels of MDA in the different studied groups: A: Dams B: Pups. Data are presented as mean \pm SD ( $n=6$ for each group). A $p$ value $\leq 0.05$ was considered statistically significant. ${ }^{\text {a: }}$ : significant against the control group. ${ }^{\text {b: }}$ significant against GA3-treated group.
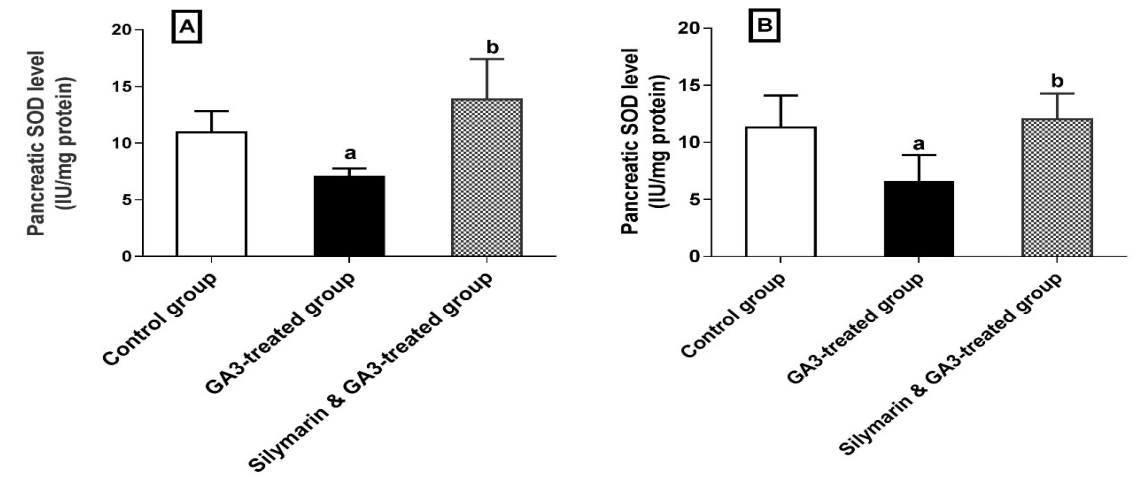

Figure 2: Pancreatic tissue levels of SOD in the different studied groups: A: Dams B: Pups. Data are presented as mean \pm SD ( $n=6$ for each group). A p value $\leq 0.05$ was considered statistically significant. a: significant against the control group. ${ }^{\text {b: }}$ significant against GA3-treated group. 

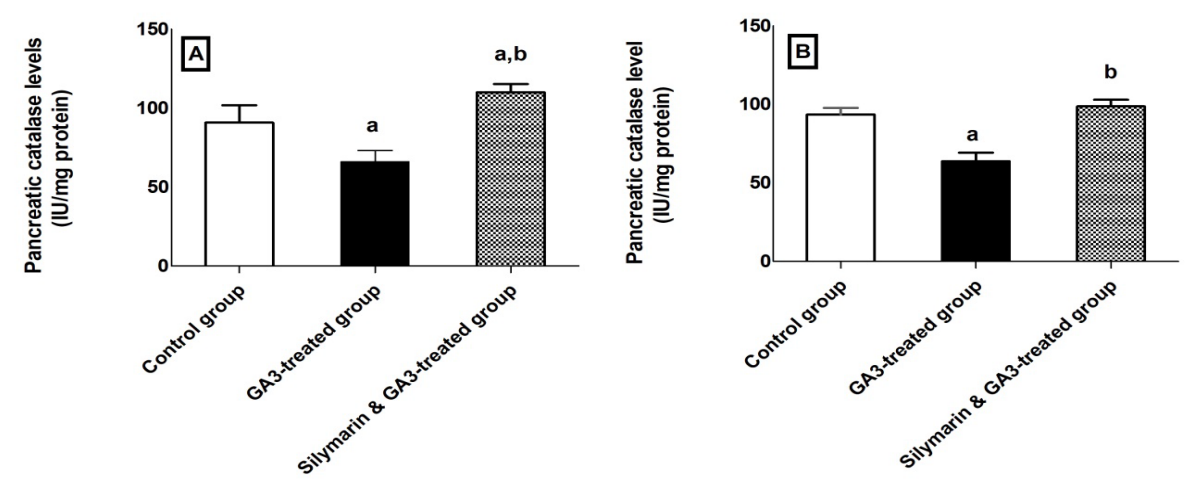

Figure 3: Pancreatic tissue levels of catalase in the different studied groups: A: Dams B: Pups. Data are presented as mean \pm SD ( $n=$ 6 for each group). A p value $\leq 0.05$ was considered statistically significant. ${ }^{\text {a: }}$ significant against the control group. ${ }^{\text {b. }}$ significant against GA3-treated group.
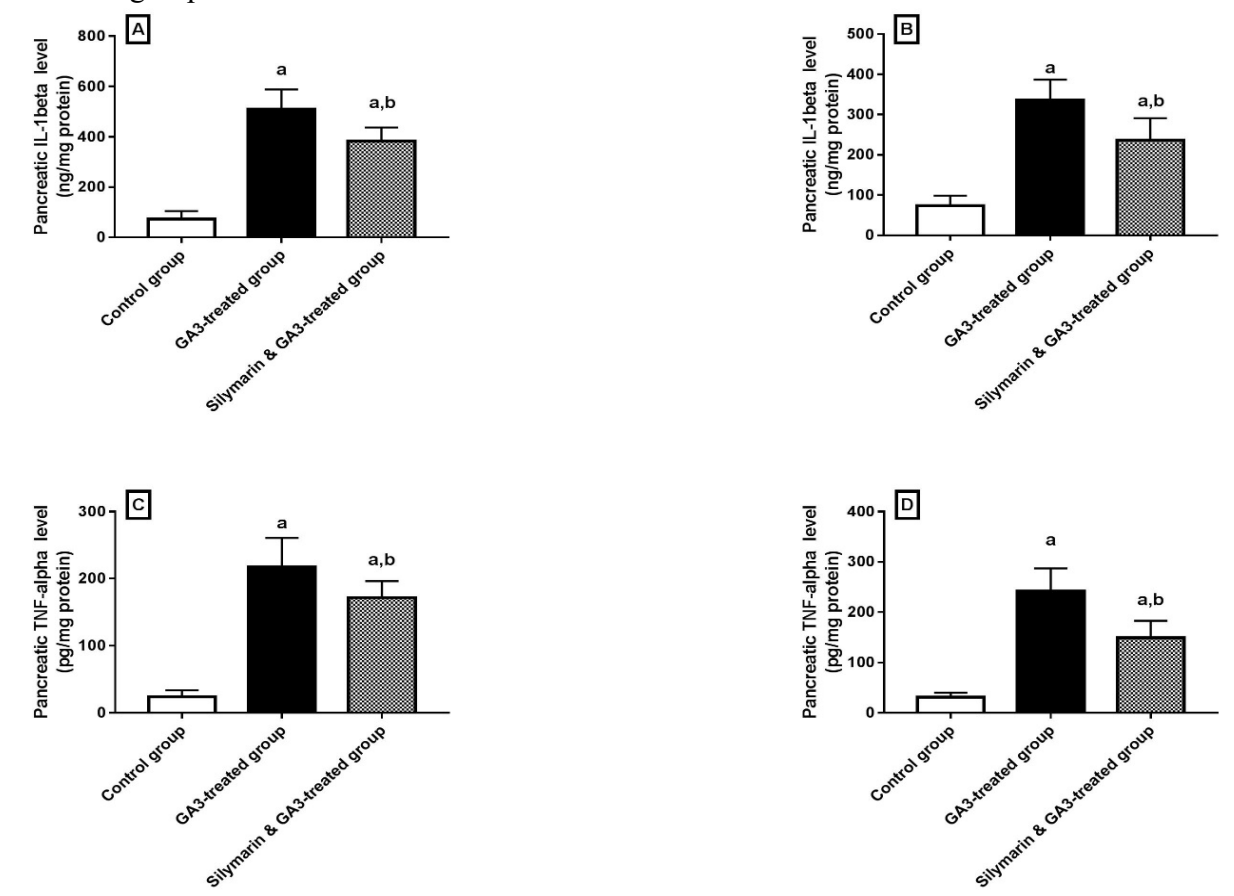

Figure 4: Pancreatic tissue levels of IL-1 $\beta$ and TNF- $\alpha$ in the different studied groups: A and C: Dams, B and D: Pups. Data are presented as mean $\pm \mathrm{SD}$ ( $\mathrm{n}=6$ for each group). A $\mathrm{p}$ value $\leq 0.05$ was considered statistically significant. ${ }^{\text {a }}$ : significant against the control group. ${ }^{\text {b: }}$ significant against GA3-treated group.

In their offspring, pups of the mothers that administered GA3 also had significantly raised levels of the pancreatic MDA as compared to pups in the control group $(p=0.001)$ (Fig 1B). Meanwhile, the pancreatic tissue levels of the antioxidant enzymes SOD \& catalase were significantly decreased in those pups in comparison with pups in the control group $(\mathrm{p}=$ 0.013 , and $\mathrm{p}=0.001$; respectively). Pups belonging to dams that received both GA3 and silymarin showed significantly lower levels of
MDA ( $p=0.011)$ and significantly higher levels of both SOD and CAT in their pancreatic tissue $(\mathrm{p}=$ $0.005, p=0.000)$ than pups in the GA3-treated group. Furthermore, levels of MDA, SOD, and CAT in those pups were insignificant when compared with pups in the control group (Fig 1B, $2 \mathrm{~B} \& 3 \mathrm{~B})$. The progeny of mothers administered GA3 showed significantly increased levels of the inflammatory mediators IL- $1 \beta$ and TNF- $\alpha$ in comparison with the control group $(p=0.000$ and $\mathrm{p}=0.000$; respectively). Silymarin administration 
in addition to GA3 to dams succeeded in suppressing the levels of these markers in their pups significantly versus those belonging to GA3treated dams $(\mathrm{p}=0.005$ and $\mathrm{p}=0.001$; respectively) but their levels remained markedly higher than pups in the control group $(p=0.000$, and $\mathrm{p}=0.000$; respectively) (Fig 4B \& 4D).

The effects of GA3 and silymarin on the pancreatic histopathology in dams and their pups:

The control dam \& their offspring in H\&E-stained sections showed that the pancreas was comprised of several organized lobules with thin interlobular connective tissue septa. Two types of tissues were noticed in the lobule namely the islets of Langerhans that were lightly stained areas intercalated within the exocrine dense stained pancreatic acini. The islet consisted of groups of cells arranged in an irregular branching and anastomosing cords with blood capillaries in between. The cells had rounded vesicular nuclei and pale acidophilic cytoplasm. The pancreatic acinar cells had a pyramidal shape containing basophilic rounded basal nuclei and apical acidophilic cytoplasm (fig 5; 1 \& 2). In GA3treated mothers, there was an apparent increased interstitial space between pancreatic lobules. Most of acinar cells showed ill-defined nuclei and highly acidophilic cytoplasm. Islets of Langerhans appeared shrunken with apparent reduced number of cells and attenuation of capillaries (fig 5; 3). In GA3-treated pups, there was an obvious increase in the stromal component in relation to the number of acini. Pancreatic acinar cells showed small dark pyknotic nuclei. There were also apparent increased interstitial spaces between pancreatic lobules (Figure 5; 4). In both silymarin-GA3 treated groups, restoration of the normal histological structure of pancreatic acini \& islets of Langerhans was noticed (Figure 5; 5 \& 6).
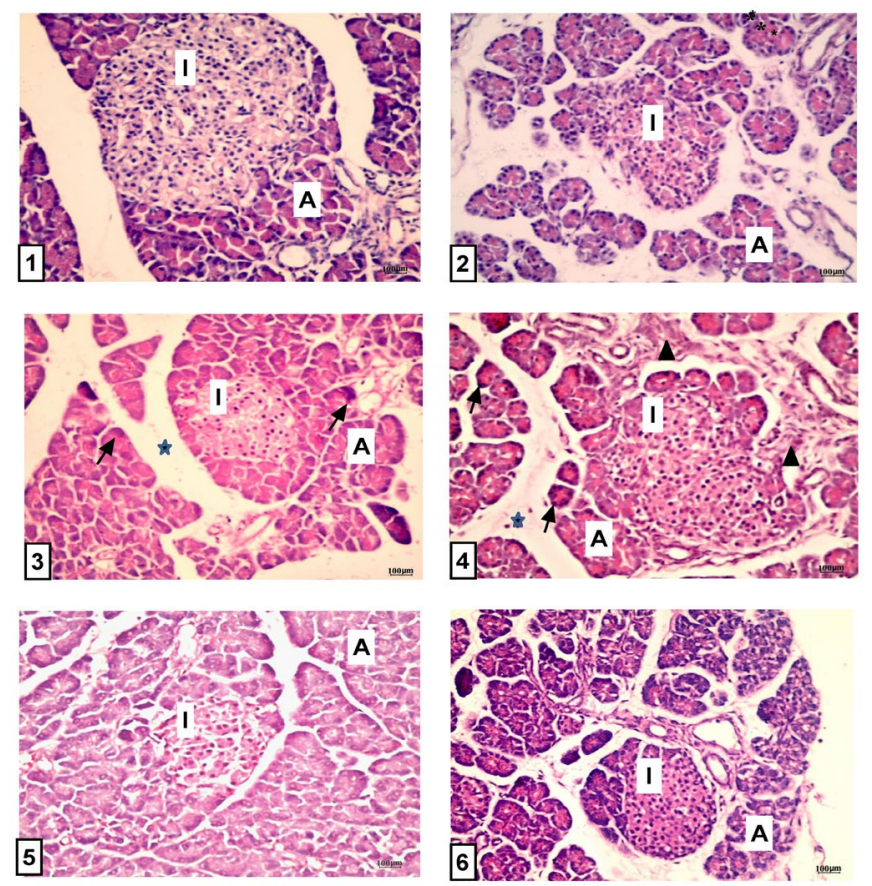

Figure 5: Light microscopic-stained sections from the pancreatic tissue of the different studied rats showing: (1) the control dam \& (2) their offspring, the pancreas is comprised of several organized lobules containing two types of tissues namely lightly-stained islets of Langerhans (I) $\&$ the exocrine dense-stained pancreatic acini (A). (3) GA3-treated mothers, there is apparent increased interstitial spaces between pancreatic lobules (asterisk). Most of acinar cells show ill-defined nuclei and highly acidophilic cytoplasm (arrow). Islets of Langerhans appear shrunken with apparent reduced number of cells. (4) Offspring of GA3-treated dams, there is an obvious increase of the stromal component in relation to number of acini (arrow head). Pancreatic acinar cells demonstrated small dark pyknotic nuclei (arrow). There is also apparent increased interstitial spaces between pancreatic lobules (asterisk). Silymarin \& GA3-treated dams (5) \& their pups (6) show restoration of the normal histological structure of pancreatic acini \& islets of Langerhans (H\&E x 100). 
Table 2: Number of islets of Langerhans in the different studied groups.

\begin{tabular}{|l|l|}
\hline \multicolumn{2}{|c|}{ Dams } \\
\hline Control group & $13.17 \pm 1.47$ \\
\hline GA3-treated group & $4.67 \pm 0.82^{\mathrm{a}}$ \\
\hline Silymarin \& GA3-treated group & $10.50 \pm 1.05^{\mathrm{a}, \mathrm{b}}$ \\
\hline \multicolumn{2}{|c|}{ Pups } \\
\hline Control group & $13.33 \pm 1.21$ \\
\hline GA3-treated group & $3.67 \pm 0.81^{\mathrm{a}}$ \\
\hline Silymarin \& GA3-treated group & $9.17 \pm 0.75^{\mathrm{a}, \mathrm{b}}$ \\
\hline
\end{tabular}

Data are presented as mean \pm SD ( $\mathrm{n}=6$ for each group). A $\mathrm{p}$ value $\leq 0.05$ was considered statistically significant. ${ }^{\mathrm{a}}$ : significant against the control group. ${ }^{\mathrm{b}}$ : significant against GA3-treated group.

Moreover, the morphometric results showed that number of islets of Langerhans in the pancreas of dams that received GA3 was significantly reduced in comparison to the control group ( $<$ 0.0001). Dams administered silymarin concurrently with GA showed an increased number of islets of Langerhans compared with the GA3-treated group $(p<0.0001)$. However, still the number of islets of Langerhans in those rats was lower than the control group $(\mathrm{p}<0.01)$. In the offspring of mothers given GA3, number of islets of Langerhans was significantly less than that in pups belonging to the control group $(\mathrm{p}<0.0001)$. However, an increased number of islets of Langerhans in pups belonging to GA3 \& silymarin treated group in comparison with the pups belonging to GA3-treated group was observed ( $\mathrm{p}<$ 0.0001). The pups in GA3 \& silymarin treated group had reduced number of islets of Langerhans when compared with the control group ( $\mathrm{p}<$ 0.0001) (Table 2).

\section{Discussion}

The available information is scarce about the toxic effects of GA3 on the mammalian pancreatic tissues and how silymarin could protect against such effects. Moreover, it was determined previously that residues of GA3 were detected in highest amounts in milk from dams exposed to oral consumption of GA3 during late pregnancy \& early lactation (24). Based on these data, the current study was designed to evaluate the probable protective effects of silymarin against the toxic influence of GA3 on the pancreatic functions in lactating dams \& also in their offsprings.

This study revealed that GA3-treated dams $\&$ their pups had significantly increased levels of serum glucose and reduced levels of serum insulin compared with the controls. The decreased insulin levels were supported by our morphometric results that revealed a significantly reduced Langerhans islet number in the pancreas. This disturbed endocrine function of the pancreas could progress into manifest $\mathrm{DM}$ in dams or their offsprings. Moreover, our results illustrated that the serum amylase levels were also significantly increased in mothers given GA3 and their progeny. A similar finding was obtained previously (27). The altered functions of both endocrine and exocrine pancreatic cells not only in dams administered GA3 but also in their pups were also supported by the histopathological findings in these groups as the islets of Langerhans appeared shrunken with apparent reduced number of cells and most of acinar cells had ill-defined nuclei and highly 
acidophilic cytoplasm. Our results were in agreement with Abd-El- Aty and Masoud (27). The presence of chemical toxins that altered exocrine \& also the endocrine cells could result in a marked increased incidence of acute pancreatitis with elevated mortality rates (28). Mirmalek et al. (29) documented that elevated serum amylase activities are the most frequently used diagnostic biomarkers in acute pancreatitis, hence the increased serum amylase levels might suggest the occurrence of pancreatitis.

Our results showed that GA3 significantly elevated levels of MDA, the lipid peroxidation endproduct, and decreased levels of SOD \& CAT in the pancreatic tissue of GA3-exposed mothers \& their offspring. These data supported that oxidative imbalance might be the possible pathophysiological pathway of GA3-induced pancreatic injury obtained in this study because the antioxidant enzymes found locally in the tissues are considered the first defense mechanism against damage produced by free radicals as reported by Moloudizargari et al. (30). This oxidative ability of GA3 was in concordance with other researches performed on different organs e.g. kidney and liver (23, 31-33). Furthermore, Hosseinchi et al. (33) reported a positive relationship between PGRs and production of ROS that might explain the increased pancreatic tissue MDA levels found in this study. The mechanism of GA3-induced oxidative stress probably results from the activation of microsomal monooxygenase that converts GA3 to reactive metabolites, and the induction of cytochrome-P450 that enhances ROS production in mammalian tissues (34). The reduced activity of SOD in this study is probably the main causative agent for ROS-mediated cell damages as it is the main enzyme responsible for converting superoxide radicals to less toxic substances $\left(\mathrm{H}_{2} \mathrm{O}_{2} \& \mathrm{O}_{2}\right)$ according to Ghobadi et al. (35).

Moreover, the oxidative ability of GA3 might be due to the stimulated inflammatory response as a result of enhanced release of substance P levels that promotes degranulation of mast cells (36). The inflammatory response was evidenced in the current study by marked increased IL- $1 \beta$ and TNF- $\alpha$ levels in GA3-treated rats compared to the control rats. The injured acinar cells were postulated to be the major source of inflammatory cytokines, triggering chemotaxis of excessive leucocytes with further tissue damage (37).

This state of oxidative stress \& local inflammation in the pancreas resulted in pancreatic damage with altered endocrine and exocrine functions of the pancreas in dams that were administered GA3 and also in their offspring. Tissue oxidative and inflammatory damage was verified by the structural alterations observed in the pancreatic tissue of dams that were administered GA3 and their pups. The apparent increased interstitial spaces between the pancreatic lobules might denote the presence of interstitial edema. Edema in addition to the degenerated acinar cells with ill-defined nuclei and highly acidophilic cytoplasm are indicative signs of early pancreatitis as demonstrated previously by Chowdhury et al. (38) and Abd-El- Aty and Masoud (27). Oxidative stress is incriminated in the occurrence of pancreatitis via zymogen degranulation, tissue necrosis, and increased activity of amylase (39). Islets of Langerhans in this study also appeared changed under the effect of GA3. 
They were shrunken with apparent reduced number of cells. This might be attributed to the damaged nuclear DNA by oxidative disequilibrium and inflammation (40). Oxidative stress could result in dysfunction of the $\beta$-cells with a consequent reduced capacity of insulin secretion and later development of diabetes mellitus (6). These tissue-damaging effects of GA3 may be caused by depletion of the antioxidant enzyme system disturbing the cellular defense mechanisms against toxicity originated by excessive generation of free radicals (41).

Interestingly, oral administration of silymarin concurrently with GA3 to mothers succeeded in counteracting the disturbed biochemical parameters \& the histopathological changes in the pancreas induced by GA3. Silymarin significantly reduced serum glucose levels, increased serum insulin levels and the pancreatic content of islets of Langerhans, and decreased the serum levels of amylase compared with the GA3-treated dams and their pups. Moreover, the histopathological appearance of the pancreas was restored to normal in those rats. The improvement of blood glucose level after silymarin intake might be mediated by the improved pancreatic structure and the enhancement of insulin secretion via the increased number of islets of Langerhans observed in our study. Similar results were obtained by silymarin when used against diabetes mellitus $(42,43)$.

The current study showed also that silymarin significantly reduced the levels of MDA, IL-1 $\beta$ \& TNF- $\alpha$ and improved the levels of SOD \& CAT antioxidant enzymes in the pancreatic tissue of dams and their pups versus the GA3-treated dams and their pups. Restoration of the normal activity of SOD \& CAT after silymarin supplementation is in partial concordance with Kheiripour et al. (43) who found increased activity of CAT in hepatic tissue after oral intake of silymarin for 60 days. The CAT enzyme protects SOD from inactivation by peroxides. SOD also safeguards CAT against the inhibitory action of superoxide anion. Hence, the equilibrium of both enzymes would be necessary for the removal of superoxide anion and peroxides in the affected tissues (34). The high antioxidant potential of silymarin is postulated as strong validation for its antidiabetic effects (44).

The obvious inhibitory action of silymarin on the free radical generation in both dams \& pups could be mediated through suppressing the activities of NADPH oxidase and $\alpha$-ketoglutarate dehydrogenase enzymes which are located in the mitochondria and considered the main source of ROS. The prominent antioxidant capability of silymarin is most likely derived from its phenolic content being higher than the flavonoid content (45). The polyphenolic constituents of silymarin interact with cytoplasmic transcription factor signaling pathway as the nuclear factor erythroid 2-related factor 2/ Kelch ECH associated protein 1 (Nrf2/Keap1), with consequent nuclear translocation of Nrf2 resulting in upregulation of gene encoding the antioxidant enzymes in cells as SOD and CAT (46).

The suppressed levels of IL- $1 \beta$ and TNF- $\alpha$ in dams and their pups after silymarin administration were comparable to the findings of Lu et al (47) and Kim et al(48). Silibinin, a major active constituent of silymarin, might explain the reduced cytokines production by mast cells via prohibiting NF-K $\beta$ pathway so that reducing 
apoptosis and preserve viability and functions of pancreatic cells (49). Lu, Huang (47) found that silymarin reduced the elevated blood glucoseassociated increase in the formation of IL1 $\beta$ and TNF- $\alpha$ by macrophages via inhibiting extracellular signal-regulated kinase (ERK) 1/2 phosphorylation leading to improved insulin resistance as these mediators hinder insulin signaling pathways. Recently, Kim et al. (48) showed that silymarin exerted potent protective $\&$ therapeutic effects in acute pancreatitis via reducing the serum \& pancreatic levels of inflammatory cytokines. These anti-inflammatory effects were mediated by suppressing p38 mitogen-activated protein kinase pathway, a fundamental pathway that regulated both transcription and synthesis of inflammatory cytokines.

The ability of silymarin to restore the histopathological changes of the pancreas of both dams and pups could be explained by their ability to save the pancreas from the destructive effect of oxidation and inflammation. Soto et al.(50) reported that silymarin enhances the secretion of glucagon like peptide-1 secreted by $\alpha$-cells of islets of Langerhans that attenuates islets apoptosis and upregulates the expression of pancreatic transcription factor, Pdx1 that induces growth, proliferation, differentiation of $\beta$ cells. This might also explain the improved insulin secretion and the restored pancreatic histological structure noticed in dams and pups of our study.

\section{Conclusion}

Our study illustrated that exposure to GA3 during late gestation and early lactation periods impaired both endocrine and exocrine pancreatic functions. Thus, this toxin should be applied with caution \& its level in agricultural products should be assessed. The study revealed also that concurrent administration of silymarin with GA3 significantly attenuated biochemical and histological features induced by GA3 not only in dams but also in their pups. These beneficial effects of silymarin might be caused by its antioxidant and anti-inflammatory potential.

\section{Limitations}

Lack of financial support does not allow the authors to investigate in depth the mechanisms of GA3-induced pancreatic dysfunction \& the beneficial effects of silymarin.

\section{Recommendations}

Further studies are required to identify other molecular mechanisms involved in GA3induced pancreatic dysfunction and its modulation by silymarin. GA3 should be used under strict control and its concentration in soil and plants and should be checked regularly.

\section{Conflict of interest}

None

\section{References}

1. Osborne D, McManus M. Hormones, signals and target cells in plant development. Abundant Vol1 (Cambridge University Press). 2005:266.

2. Ross JJ, Weston DE, Davidson SE, Reid JB. Plant hormone interactions: how complex are they? Physiologia plantarum. 2011;141(4):299-309.

3. Chaari-Rkhis A, Maalej M, SO Messaoud S, Drira N. In vitro vegetative growth and flowering of olive tree in response to GA3 treatment. African Journal of Biotechnology. 2006; 5(22): 2097-302.

4. de Oliveira $\mathbf{J}$, Rodrigues $\mathbf{C}$, Vandenberghe LP, Câmara MC, Libardi N, Soccol CR. 
Gibberellic acid production by different fermentation systems using citric pulp as substrate/support. BioMed research international. 2017;2017.

5. Schwechheimer C, Willige BC. Shedding light on gibberellic acid signalling. Current opinion in plant biology. 2009;12(1):57-62.

6. Saleh A, Anwar MM, Zayed AE, Eldeen MESE, Afifi G, Alnashiri HM, et al. Impact of Ginkgo biloba extract and magnetized water on the survival rate and functional capabilities of pancreatic $\beta$-cells in type 2 diabetic rat model. Diabetes, metabolic syndrome and obesity: targets and therapy. 2019;12:1339.

7. Salih L, Al-mahdawi F, Al-salihi A. Teratological effect of pregabalin drug on the prenatal development of the cerebellum in the albino rats. International Journal of Recent Scientific Research. 2014;5(7):1381-5.

8. Abd El-Latief $\mathbf{H}$. Hepatotoxicity induced by gibberellic acid (GA3) in adult male albino rats. Int J Adv Res 2016;4(12):2677-87.

9. Troudi A, Mahjoubi Samet A, Zeghal N. Hepatotoxicity induced by gibberellic acid in adult rats and their progeny. Experimental and toxicologic pathology : official journal of the Gesellschaft fur Toxikologische Pathologie. 2010;62(6):637-42.

10. Husseiny N, Farag AI, Mohammed HO. Histological and Immunohisto-chemical Study of Toxic Effect of Gibberellic Acid Postnatally on Renal Cortex of Albino Rats. Egyptian Journal of Histology. 2020.

11. Eslami B, Naddafi K, Rastkari N, Rashidi BH, Djazayeri A, Malekafzali H. Association between serum concentrations of persistent organic pollutants and gestational diabetes mellitus in primiparous women. Environmental research. 2016;151:706-12.
12. Bhattamisra SK, Siang TC, Rong CY Annan NC, Sean EH, Xi LW, et al. Type-3c diabetes mellitus, diabetes of exocrine pancreas-an update. Current diabetes reviews. 2019;15(5):382-94.

13. Bayoumy NM, El-Shabrawi MM, Leheta OF, Abo El-Ela AEDM, Omar HH. Association of ELMO1 gene polymorphism and diabetic nephropathy among Egyptian patients with type 2 diabetes mellitus. Diabetes/Metabolism Research and Reviews. 2020:e3299.

14. Soliman A. Diabetes mellitus in Egypt in short. J Diabetes Metab. 2013;4(2).

15. Arafa N, Amin G. The epidemiology of diabetes mellitus in Egypt: Results of a national survey. Egyptian Journal of Community Medicine. 2010;28(3):29-43.

16. Baker NA, Karounos M, English V, Fang J, Wei Y, Stromberg A, et al. Coplanar polychlorinated biphenyls impair glucose homeostasis in lean C57BL/6 mice and mitigate beneficial effects of weight loss on glucose homeostasis in obese mice. Environmental health perspectives. 2013;121(1):105-10.

17. Ghoneim FM, Arafat EA. Histological and histochemical study of the protective role of rosemary extract against harmful effect of cell phone electromagnetic radiation on the parotid glands. Acta histochemica. 2016;118(5):47885.

18. AbouZid SF, Chen SN, Pauli GF. Silymarin content in Silybum marianum populations growing in Egypt. Industrial crops and products. 2016;83:729-37.

19. Althagafy HS, Meza-Avina ME, Oberlies NH, Croatt MP. Mechanistic study of the biomimetic synthesis of flavonolignan 
diastereoisomers in milk thistle. The Journal of organic chemistry. 2013;78(15):7594-600.

20. Kazazis CE, Evangelopoulos AA, Kollas A, Vallianou NG. The therapeutic potential of milk thistle in diabetes. The review of diabetic studies : RDS. 2014;11(2):167-74.

21. Abdelmageed Marzook E, Abdel-Aziz A, Abd El-Moneim A, Mansour H, Atia K, Salah N. MicroRNA-122 expression in hepatotoxic and $\gamma$-irradiated rats pre-treated with naringin and silymarin. Journal of Radiation Research and Applied Sciences. 2020;13(1):47-55.

22. Goldman JM, Murr AS, Cooper RL. The rodent estrous cycle: characterization of vaginal cytology and its utility in toxicological studies. Birth Defects Research Part B: Developmental and Reproductive Toxicology. 2007;80(2):84-97.

23. Troudi A, Ben Amara I, Soudani N, Samet AM, Zeghal N. Oxidative stress induced by gibberellic acid on kidney tissue of female rats and their progeny: biochemical and histopathological studies. Journal of physiology and biochemistry. 2011;67(3):30716.

24. Troudi A, Bouaziz H, Soudani N, Ben Amara I, Boudawara T, Touzani H, et al. Neurotoxicity and oxidative stress induced by gibberellic acid in rats during late pregnancy and early postnatal periods: biochemical and histological changes. Experimental and toxicologic pathology : official journal of the Gesellschaft fur Toxikologische Pathologie. 2012;64(6):583-90.

25. Turgut F, Bayrak O, Catal F, Bayrak R, Atmaca AF, Koc A, et al. Antioxidant and protective effects of silymarin on ischemia and reperfusion injury in the kidney tissues of rats.
International urology and nephrology. 2008;40(2):453-60.

26. Gornall AG, Bardawill CJ, David MM. Determination of serum proteins by means of the biuret reaction. Journal of biological chemistry. 1949;177(2):751-66.

27. Abd-El- Aty O, Masoud R. Potential Toxicity of Plant Growth Regulator Gibberellic acid (GA3) on the Pancreatic Structures and Functions in the albino rat. 2016. 2016;2(2):11-22.

28. Greenberg JA, Hsu J, Bawazeer M, Marshall J, Friedrich JO, Nathens A, et al. Clinical practice guideline: management of acute pancreatitis. Canadian journal of surgery Journal canadien de chirurgie. 2016;59(2):12840.

29. Mirmalek SA, Gholamrezaei Boushehrinejad A, Yavari H, Kardeh B, Parsa Y, Salimi-Tabatabaee SA, et al. Antioxidant and anti-inflammatory effects of coenzyme Q10 on L-arginine-induced acute pancreatitis in rat. Oxidative medicine and cellular longevity. 2016;2016(Article ID (5818479)):1-8.

30. Moloudizargari M, Asghari MH, Ghobadi E, Fallah M, Rasouli S, Abdollahi M. Autophagy, its mechanisms and regulation: implications in neurodegenerative diseases. Ageing research reviews. 2017;40:64-74.

31. Abdel Rahm M, Abdel Atty Y, Abdul Rahman M, Sabry M. Structural changes induced by gibberellic acid in the renal cortex of adult male albino rats MOJ Anat \& Physiol; 3(1): 1-7. 2017;3(1):1-7.

32. Alsemeh AE, Moawad RS, Abdelfattah ER. Histological and biochemical changes induced by gibberellic acid in the livers of pregnant albino rats and their offspring: ameliorative 
effect of Nigella sativa. Anatomical science international. 2019;94(4):307-23.

33. Hosseinchi M, Soltanalinejad F, Najafi G, Roshangar L, editors. Effect of gibberellic acid on the quality of sperm and in vitro fertilization outcome in adult male rats. Veterinary research forum: an international quarterly journal; 2013: Faculty of Veterinary Medicine, Urmia University, Urmia, Iran.

34. Suriamurthy M, Srikuma K. Effect of plant hormone gibberellic acid-3 on rat testicular biomarkers and its histology. . 2017;6(9):1276 -90 .

35. Ghobadi E, Moloudizargari M, Asghari MH, Abdollahi M. The mechanisms of cyclophosphamide-induced testicular toxicity and the protective agents. Expert opinion on drug metabolism \& toxicology. 2017;13(5):525-36.

36. Erin N, Afacan B, Ersoy Y, Ercan F, Balcı MK. Gibberellic acid, a plant growth regulator, increases mast cell recruitment and alters Substance $P$ levels. Toxicology. 2008;254(1-2):75-81.

37. Kaukonen KM, Bailey M, Pilcher D, Cooper DJ, Bellomo R. Systemic inflammatory response syndrome criteria in defining severe sepsis. New England Journal of Medicine. 2015;372(17):1629-38.

38. Chowdhury P, Nishikawa M, Blevins Jr GW, Rayford PL. Response of Rat Exocrine Pancreas to High-Fat and High-Carbohydrate Diets (44496). Proceedings of the Society for Experimental Biology and Medicine. 2000;223(3):310-5.

39. Abu-Hilal M, McPhail M, Marchand L, Johnson CD. Malondialdehyde and superoxide dismutase as potential markers of severity in acute pancreatitis. Jop. 2006;7(2):185-92.

40. Chen Z, Jiang H, Wan Y, Bi C, Yuan Y. H 2 $\mathrm{O}$ 2-induced secretion of tumor necrosis factor- $\alpha$ evokes apoptosis of cardiac myocytes through reactive oxygen species-dependent activation of p38 MAPK. Cytotechnology. 2012;64(1):65-73.

41. Ali M, Nasr El-Din W, Anter S. Possible ameliorative effect of Vitamin $\mathrm{C}$ on cerebellar toxicity induced by gibberellic acid during late pregnancy and early postnatal periods in albino rats. Eur J Anat 22 (4): 345-354 2018;22(4):345-54.

42. Amniattalab A, Malekinejad H, Rezabakhsh A, Rokhsartalab-Azar S, Alizade-Fanalou S. Silymarin: A Novel Natural Agent to Restore Defective Pancreatic beta Cells in Streptozotocin (STZ)-induced Diabetic Rats. Iranian journal of pharmaceutical research : IJPR. 2016;15(3):493-500.

43. Kheiripour N, Karimi J, Khodadadi I, Tavilani H, Goodarzi MT, Hashemnia M. Silymarin prevents lipid accumulation in the liver of rats with type 2 diabetes via sirtuin 1 and SREBP-1c. Journal of basic and clinical physiology and pharmacology. 2018;29(3):301-8.

44. Jose MA, Abraham A, Narmadha MP. Effect of silymarin in diabetes mellitus patients with liver diseases. Journal of pharmacology \& pharmacotherapeutics. 2011;2(4):287-9.

45. Pientaweeratch S, Panapisal V, Tansirikongkol A. Antioxidant, anticollagenase and anti-elastase activities of Phyllanthus emblica, Manilkara zapota and silymarin: An in vitro comparative study for 
anti-aging applications. Pharmaceutical

biology. 2016;54(9):1865-72.

46. Surh YJ. NF-kappa B and Nrf2 as potential chemopreventive targets of some antiinflammatory and antioxidative phytonutrients with anti-inflammatory and antioxidative activities. Asia Pacific journal of clinical nutrition. 2008;17 Suppl 1:269-72.

47. Lu C-P, Huang C-Y, Wang S-H, Chiu C-H, Li L-H, Hua K-F, et al. Improvement of hyperglycemia in a murine model of insulin resistance and high glucose-and inflammasome-mediated IL- $1 \beta$ expressions in macrophages by silymarin. Chemicobiological interactions. 2018;290:12-8.

48. Kim MJ, Kim DU, Choi JW, Kim DG, Song HJ, Bae GS, et al. Silymarin Attenuates the Severity of Cerulein-Induced Acute Pancreatitis. Pancreas. 2020;49(1):89-95.

49. Kim B-R, Seo H-S, Ku J-M, Kim G-J, Jeon CY, Park JH, et al. Silibinin inhibits the production of pro-inflammatory cytokines through inhibition of NF- $\mathrm{B}$ signaling pathway in HMC-1 human mast cells. Inflammation Research. 2013;62(11):941-50.

50. Soto C, González I, López K. Improvement of impaired glucose tolerance by the increase in secretion of pancreatic GLP-1 induced by silymarin in rats. International Journal of Latest Research in Science and Technology. 2018;7(1):15-21. 